\title{
3D model related to the publication: From limb to fin: an Eocene protocetid forelimb from Senegal sheds new light on the early locomotor evolution of early cetaceans.
}

\author{
Vautrin Quentin ${ }^{1}$, Lihoreau Fabrice ${ }^{1}$, Sambou Bernard ${ }^{2}$, Thiam Moustapha ${ }^{2}$, Martin Jérémy E. ${ }^{3}$, Tabuce Rodolphe ${ }^{1}$, \\ Adnet Sylvain $^{1}$, Lebrun Renaud ${ }^{1}$, Charruault Anne-Lise ${ }^{1}$, Sarr Raphaël ${ }^{2 *}$, Hautier Lionel ${ }^{1 *}$ \\ ${ }^{1}$ Institut des Sciences de l'Evolution de Montpellier, Université Montpellier 2, CNRS, IRD, Cc 064; place Eugène Bataillon, 34095 Montpellier Cedex 5, \\ France; \\ ${ }^{2}$ Laboratoire de Biostratigraphie et Sédimentologie, Département de Géologie, Faculté des Sciences et Techniques, Université Cheikh-Anta-Diop de \\ Dakar, B. P. 5005 Dakar-Fann, Sénégal. \\ ${ }^{3}$ Univ. Lyon, ENS de Lyon, Université Claude Bernard Lyon 1, CNRS, UMR 5276 Laboratoire de Géologie de Lyon: Terre, Planètes, Environnement, \\ F-69342 46 Allée d'Italie, Lyon, France
}

*Corresponding authors: Dr. Lionel Hautier and Pr. Raphaël Sarr. E-mails: lionel.hautier@univ-montp2.fr and rsarr@ucad.sn

\section{Abstract}

The present 3D Dataset contains the 3D model analyzed in Vautrin et al. (2019), Palaeontology, From limb to fin: an Eocene protocetid forelimb from Senegal sheds new light on the early locomotor evolution of early cetaceans. https://doi.org/10.1111/pala.12442

Keywords: Cetacea, Eocene, Forelimb, Protocetidae, Senegal

Submitted:2019-04-26, published online:2019-08-26. https://doi.org/10.18563/journal.m3.92

\section{Inv. nr. \\ SNTB2011-01 3D model of an articulated forelimb of a \\ Carolinacetus-like protocetid from \\ Senegal}

Table 1. Corresponding specimen and model. SNTB2011-01 is stored in the collection of the department of geology of the University Cheikh Anta Diop in Dakar.

\section{INTRODUCTION}

We present here the 3D model of a cetacean specimen discovered in middle Eocene phosphate deposits from Taïba Ndiaye (Western Senegal), which enabled for the first detailed description of an articulated forelimb in a derived protocetid found outside Asia (Vautrin et al. 2019). SNTB2011-01 consists of bones of a single individual removed from a limestone block after acid preparation. It includes two nearly complete thoracic vertebrae, three ribs, a pedal phalanx, a patella, a fragment of a right humerus, a complete right ulna, a fragmentary right radius and a right autopod. Only the elements of the stylopod, zeugopod, and autopod are presented here. SNTB2011-01 is stored in the collection of the department of geology of the University Cheikh Anta Diop in Dakar.

\section{METHODS}

The bones of SNTB 2011-01 were imaged using a NextEngine 3-dimensional desktop scanner (NextEngine, Inc, Santa Monica, California) for the stylopod and zeugopod, and with highresolution microtomography $(\mu \mathrm{CT})$ at the MRI platform of the Institut des Sciences de l'Evolution de Montpellier (ISE-M) for the autopod. The 3D surfaces of the autopod elements were extracted semi-automatically with AVIZO 9.2 (FEI) using the segmentation threshold selection tool. 3D virtual restoration was performed with MorphoDig software (Lebrun 2018). The metacarpals III to V, the pyramidal, the lunar, the scaphoid, the unciform, the magnum, and the trapezoid were all found in anatomical connection and were left in their original position. The trapezium was moved and repositioned in articulation with the scaphoid. The metacarpal II was moved distally to articulate with the magnum. Following the reconstructions of Maiacetus inuus, Rodhocetus kasranii, and Dorudon atrox (Gingerich et al. 2001, 2009; Uhen 2004), the pisiform, the metacarpal I, and the proximal, medial and distal phalanges were repositioned in connection with other elements. The 3D surface model of the complete forelimb (Fig. 1 and table 1) is provided in .ply format, and can therefore be opened with a wide range of freeware.

\section{ACKNOWLEDGEMENTS}

We thank the Department of Geology of the University CheikhAnta-Diop of Dakar, especially Professor El Hadji Sow (Head of Department). We are very grateful to M. El Hadji Mansour Sambe (Director of Mineral resources and Geology) and M. Ibrahima Gaye (Director of the Mine site) for providing full access to the quarry of Taïba Ndiaye and support from the local miners (especially F. Lassy and C. Toumani). We are also very grateful to Laurent Marivaux (Institut des Sciences de l'Evolution de Montpellier) for his support and advice. 3D data acquisitions were partly performed using the $\mu \mathrm{CT}$ facilities of the MRI platform member of the national infrastructure France-BioImaging supported by the French National Research Agency (ANR-10-INBS-04, «Investments for the future $\gg$ ), and of the Labex CEMEB (ANR-10-LABX-0004) and NUMEV (ANR-10-LABX-0020). We also thank Suzanne Jiquel (Institut 

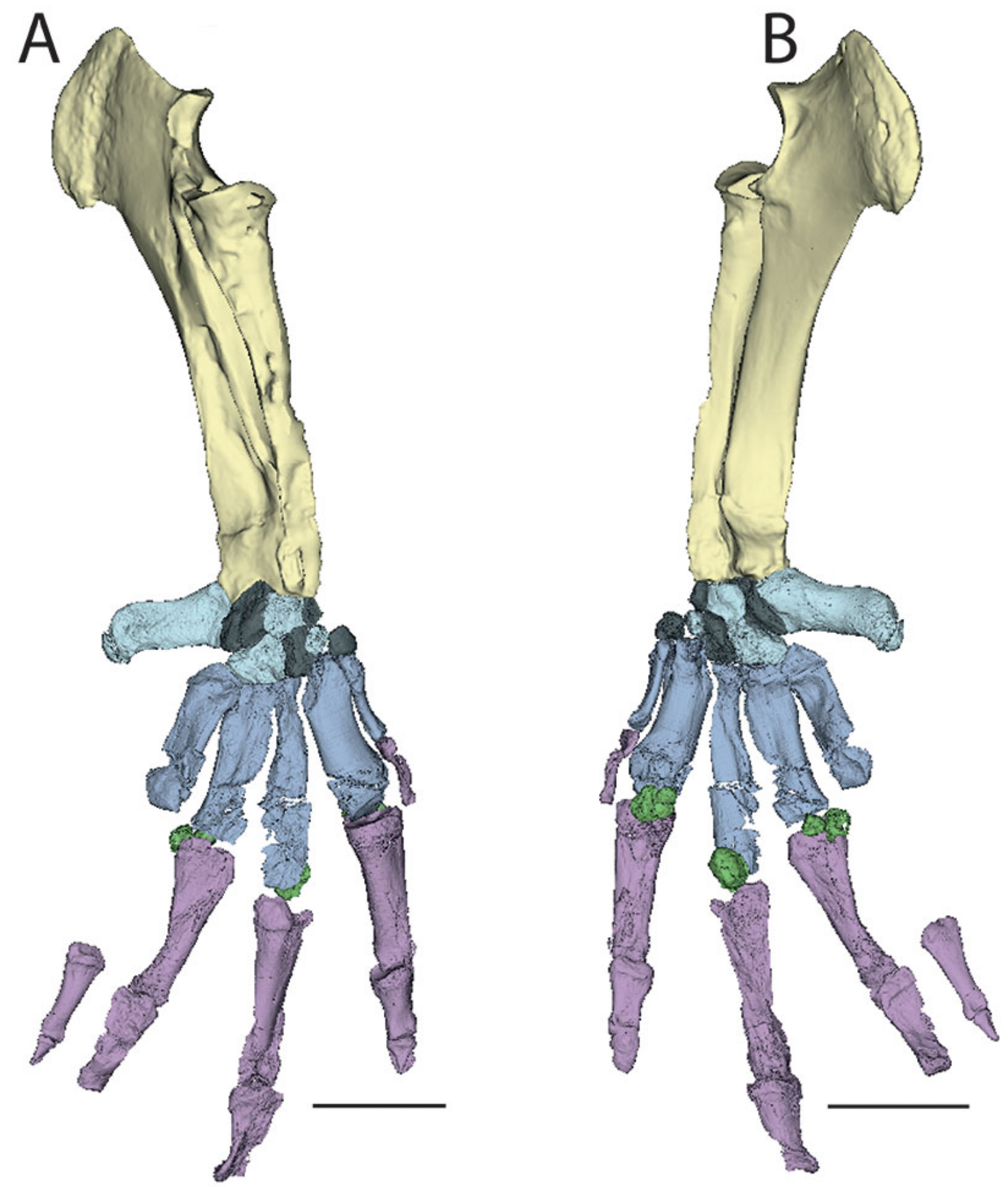

Figure 1. 3D reconstruction of the Senegalese right forelimb (SNTB 2011-01) in dorsal (A) and palmar (B) views. The zeugopod elements are coloured in yellow, carpals are in cyan, metacarpals in blue, phalanges in violet, and sesamoids in green. Scale bar: $5 \mathrm{~cm}$. 
des Sciences de l'Evolution de Montpellier) for access to comparative material. This research is part of the PaleoSen project (www.paleosen.com), and was supported by the French ANRPALASIAFRICA Program (ANR-08-JCJC-0017), PICS-CNRS, the International Exchange Scheme of the Royal Society, and the National Geographic Society's Global Exploration Fund (Northern Europe). Lionel Hautier also gratefully acknowledges Sidney Sussex College (Cambridge, UK).

\section{BIBLIOGRAPHY}

Gingerich P. D., Haq M., Zalmout I. S., 2001. Origin of whales from early artiodactyls: hands and feet of Eocene Protocetidae from Pakistan. Science, 293, 2239-2242. https://doi.org/10.11 26/science.1063902

Gingerich, P. D., Ul-Haq, M., von Koenigswald, W., Sanders, W. J., Smith, B. H., Zalmout, I. S. 2009. New protocetid whale from the Middle Eocene of Pakistan: birth on land, precocial development, and sexual dimorphism. PloS ONE, 4, 1-20. https://doi.org/10.1371/journal.pone.0004366

Uhen, M. D. 2004. Form, function, and anatomy of Dorudon atrox (Mammalia, Cetacea): An archaeocete from the middle to late Eocene of Egypt. Papers in Palaeontology, 34, 1-197.

Lebrun, R. 2018. MorphoDig, an open-source 3D freeware dedicated to biology. IPC5, Paris, France.

Vautrin, Q., Lihoreau, F., Sambou, B., Thiam, M., Martin J.E., Tabuce, R., Adnet, S., Lebrun, R., Charruault, A-L., Sarr, R., Hautier, L. 2019. From limb to fin: an Eocene protocetid forelimb from Senegal sheds new light on the early locomotor evolution of early cetaceans. Palaeontology. https://doi.org/10. 1111/pala.12442 